\title{
Epidemiology and Sequelae of Workplace Hand Injuries at a Tertiary Trauma Care Centre
}

\author{
Rohini Prasad*, Arivind Bhamidi, Arunkumar Rajeswaran, Subramaniam Muthukumar, \\ Porkodi Kothandaraman, Meenatchi Sivaraj \\ Department of Plastic, Reconstructive and Hand Surgery, Parvathy Hospital, Chennai, India \\ Email: ${ }^{\text {rohinibph@yahoo.com }}$
}

Received 26 February 2014; revised 22 March 2014; accepted 29 March 2014

Copyright (C) 2014 by authors and Scientific Research Publishing Inc.

This work is licensed under the Creative Commons Attribution International License (CC BY). http://creativecommons.org/licenses/by/4.0/

(c) (i) Open Access

\begin{abstract}
Aims \& Objectives: To study the epidemiology of workplace hand injuries, to understand relation between mode of injury and prognosis, to investigate into the possible contributing factors and to study the Socio-economic impact. Design of Study: For the prospective study there were 2 sources of data: 1) Proforma which was filled by the hand surgeon and 2) A questionnaire that was filled up by safety officer. For the retrospective study case, sheets were retrieved from the Medical Records section and a telephonic or personal interview was carried out by a single interviewer. Setting: Department of Plastic and Reconstructive Surgery, Parvathy Hospital, Chennai, India. Patients: A total of 419 industrial injury patients treated from January 2008 to January 2013 were included in the study. Further follow-up regarding return to work and residual disability continues. Main Outcome Measures: Personal details (Age, Gender, Handedness, Work experience, Income). Type of injury, mode of injury, day and time of injury, treatment given, disability and number of working days lost were measured. Results: Those workers who were experienced less than 6 months had more workplace injuries and the commonest contributing factor was co-workers carelessness followed by long working hours and faulty machinery. Maximum injuries occurred on Monday and morning shift. Conclusions: Constant supervision of trainees for 2 years, shorter working hours with regular breaks, regular health checkups for personnel, regular servicing of machines can prevent occurrence of hand injuries. Corrective surgery within 6 hours, systematic and protocol based physiotherapy and rehabilitation can reduce the economic loss and disability arising out of work place injuries.
\end{abstract}

\section{Keywords}

Hand Injury, Disability, Prevention

\footnotetext{
${ }^{*}$ Corresponding author.
}

How to cite this paper: Prasad, R., Bhamidi, A., Rajeswaran, A., Muthukumar, S., Kothandaraman, P. and Sivaraj, M. (2014) Epidemiology and Sequelae of Workplace Hand Injuries at a Tertiary Trauma Care Centre. Surgical Science, 5, 150-158. http://dx.doi.org/10.4236/ss.2014.54027 


\section{Introduction}

The very hand that gives a manual worker his livelihood can be a cause of physical and psychosocial misery if it gets injured. The economic, social and physical impact of the disability that arises out of workplace hand injuries is tremendous. We are reporting an epidemiologic study of the hand injury, the worker and the industry in a series of 419 cases from January 2008 to January 2013 that were treated at our Trauma centre which is a tertiary care centre for hand injuries [1] [2]. The best way to evolve primary and secondary preventive strategies is to thoroughly study the epidemiological characteristics of hand injuries. The study of personal details helps in identifying the socio-economic character and impact of the affected group. The study of machinery and instrumentation involved in the accident and its comparison with type of injury and final hand function helps us recognize patterns and evolve reconstructive and rehabilitative strategies. An insight into what were the possible causative factors can help the industry to evolve preventive strategies. The time and day of week when maximum injuries occur reflects a pattern which can help industries to introspect and change work habits and culture. From the hand surgeon's point of view, the correlation between timing of surgery, type of injury, quality of repair and residual disability can help improvise reconstructive and rehabilitative strategies.

\section{Methods}

The period from January 2008 to September 2008 was a retrospective study of 80 cases. The rest of 339 cases were based on a prospective study from September 2008-January 2013. A proforma prepared for work place hand injuries was filled by the hand surgeon and the physiotherapist (Appendix 1). Another questionnaire was duly filled by a responsible authority or safety officer of the industry where the incident had taken place (Appendix 2). The injured were received in the Emergency room and given first aid, x-rays of the injured part \& amputated part of patient were taken. In case of major injuries such as elbow, arm or forearm crush with vascular injuries priority was given to resuscitate the patient. The type of surgeries ranged from simple skin suturing to skin grafting, local and distant flap cover, tendon and nerve repair with or without reconstruction, vascular repair and reimplantation. For complex crushed digits which could not be revascularised or reconstructed, a primary shortening and closure is considered. All injuries were classified as major and minor. Post operatively protocol based physiotherapy was started from the first day which includes mobilization of unaffected joints, intrinsic, and extensor strengthening, flexor strengthening according to the case specific therapy for tendon repair, fractures, nerve repair such as Kleinerts' traction, electrical stimulation, wax therapy and ultrasonic therapy was done. At the end of 3 months, the return to daily activities and professional activities are addressed and the number of working days lost, residual disability and deformity are measured.

\section{Discussion}

Hand injuries are among the most frequent injuries worldwide, constituting between $6.65 \%$ to $28.6 \%$ of all injuries and $28 \%$ of injuries to the musculoskeletal system [3]. These occur at workplace, home and in road traffic accidents. Our study evaluates the characteristics of occupational hand injuries and associated factors. Workplace hand injuries form nearly $80 \%$ of hand injuries received at our trauma centre as compared to $70 \%$ reported in a Turkish study group, 60\% in Denmark and 31\% in Kenya [4]. Based on the personal data in our series, $62 \%$ were male workers and $54 \%$ were in the age group of $16-25$ years. $65 \%$ were in the low income group (annual income less than INR 72,000) and only 8\% were self employed (Table 1). In comparison the ratio of male subjects is reported as 76\% in the US, $69 \%$ in the UK, 59\% in Denmark and $83 \%$ in Turkey. In Netherland and Denmark, hand injuries peak in the age group 10 - 14 years, 44\% in 10 - 19 years in Canada, 35\% (under 15 years) in Turkey [5]-[8]. 65\% of the victims of industrial injuries in our study were literate (10 years in school and 3 years diploma) in comparison to $41 \%$ in the Turkish study [9]-[11]. In our study $91 \%$ were right hand dominant and $42.5 \%$ had only right hand injury, $40 \%$ had bilateral hand injury and $17.5 \%$ had left hand injury [12]. In comparison, $48.5 \%$ of dominant hand injury and 51.5\% of non-dominant hand injury has been reported in a study based in Kenya [13]. In our study, mode of injury was found to be crush (33\%), cut/slicing (23\%) and combination (38\%) (Table 2). Hydraulic machines were involved in 25\%, while cutting and grinding were $29 \%, 18 \%$ respectively (Table 3). In comparison in the Hongkong based study, cut injuries formed the highest group followed by power press machine injury [14]. In our study index finger was most commonly injured single finger at $17.5 \%$ with $32 \%$ of patients having multiple finger injuries (Table 4). The terminal phalanx is most commonly injured bone in hand at $13 \%$ (Table 5). Maximum injuries occurred on Monday and morning 
Table 1. Personal details.

\begin{tabular}{|c|c|c|}
\hline S.NO & PD & WORKERS \\
\hline \multirow{5}{*}{1} & AVERAGE AGE & \\
\hline & $16-25$ & 215 \\
\hline & $26-35$ & 149 \\
\hline & $36-45$ & 45 \\
\hline & $46-55$ & 10 \\
\hline \multirow{3}{*}{2} & GENDER & \\
\hline & MALE & $62 \%$ \\
\hline & FEMALE & $38 \%$ \\
\hline \multirow{3}{*}{3} & DOMINANCE & \\
\hline & RIGHT & 381 \\
\hline & LEFT & 38 \\
\hline \multirow{3}{*}{4} & HAND INJURY & \\
\hline & RIGHT & 346 \\
\hline & LEFT & 173 \\
\hline \multirow{4}{*}{5} & SOCIOECONOMIC STATUS & \\
\hline & LOW & $65 \%$ \\
\hline & MIDDLE & $25 \%$ \\
\hline & HIGH & $10 \%$ \\
\hline \multirow{3}{*}{6} & SELF EMPLOYMENT & \\
\hline & SELF & $8 \%$ \\
\hline & INDUSTRY & $92 \%$ \\
\hline
\end{tabular}

Table 2. Mode of injury.

\begin{tabular}{ccc}
\hline S.NO & MOI & WORKERS \\
\hline 1 & CRUSH & 140 \\
2 & SLICING & 100 \\
3 & BLUNT & 79 \\
4 & MANGLED & 48 \\
5 & COMBINATION & 160 \\
6 & BURN & 21 \\
\hline
\end{tabular}

Table 3. Type of machine.

\begin{tabular}{ccc}
\hline S.NO & TOM & WORKERS \\
\hline 1 & HYDRAULIC & 106 \\
2 & CUT & 124 \\
3 & GRINDING & 78 \\
4 & SPINNING & 50 \\
5 & CONTRUCTION WORK & 64 \\
\hline
\end{tabular}

Table 4. Digits involved.

\begin{tabular}{ccc}
\hline S.NO & SOI & WORKERS \\
\hline 1 & THUMB & 58 \\
2 & INDEX & 85 \\
3 & MID & 45 \\
4 & RING & 67 \\
5 & LITTLE & 74 \\
6 & MULTIPLE & 158 \\
\hline
\end{tabular}


shift (Table 6, Table 7).

Table 8 shows the commonly performed procedures for hand injury with $19.7 \%$ of patients having undergone simple suturing, $7.8 \%$ of tendon repair, fracture fixation is $18 \%$, reconstruction is $6 \%$, skin grafting is $11.8 \%$, and $17.8 \%$ of underwent shortening and closure. In our study the most probable contributing factor to injury was co-workers carelessness found to be $24.8 \%$ (Table 9 ) followed by use of suboptimal protection gears while in a comparative study $45 \%$ reported overtime as a contributing factor. Nearly $85 \%$ of patients underwent safety training (Table 10) for an average of 3 months at their workplace before being inducted into service \& nearly $43 \%$ of the patients had a job experience of less than 6 months duration (Table 11). The Hong Kong based study reports 58\% with work experience less than 1 year. In the Hongkong based study, 61\% of workers were briefed about their jobs and $90 \%$ of them were satisfied with machine design. Table 12 shows the disability in return to daily activities and professional activities at 3 months and their relation to the time lapse between injury and treatment (Table 13).

\section{Conclusions}

Work place hand injuries constitute a significant group of injuries received at our centre. They have a three pronged effect on the individual and society-physical, psychosocial and economical. The effects are so profound and long lasting that serious thinking need be done for preventive strategies and disability reduction. Based on our survey, adequate safety training before induction along with regular safety drills and education can make a significant contribution to reduction in hand injuries. Periodic screening for medical and psychological disorders and counseling also helps.

Higher occurrence of injury in the 9 a.m. to 1 p.m. shift is an indicator of haste and anxiety being additional

Table 5. Site of injury.

\begin{tabular}{ccc}
\hline S.NO & SOI & WORKERS \\
\hline 1 & TIP & 96 \\
2 & TERMINAL PHALANX & 75 \\
3 & MIDDLE PHALANX & 48 \\
4 & PROXIMAL PHALANX & 53 \\
5 & HAND & 40 \\
6 & WRIST & 30 \\
7 & FOREARM & 45 \\
8 & CUBITAL FOSSA & 20 \\
9 & COMBINATION & 125 \\
10 & ARM & 25 \\
\hline
\end{tabular}

Table 6. Day of injury.

\begin{tabular}{ccc}
\hline S.NO & DOI & WORKERS \\
\hline 1 & SUNDAY & 34 \\
2 & MONDAY & 84 \\
3 & TUESDAY & 70 \\
4 & WEDNESDAY & 60 \\
5 & THURSDAY & 71 \\
6 & FRIDAY & 60 \\
7 & SATURDAY & 40 \\
\hline
\end{tabular}

Table 7. Time of injury.

\begin{tabular}{ccc}
\hline S.NO & TIME & WORKERS \\
\hline 1 & 5A.M. - 9 A.M. & 62 \\
2 & 9A.M. - 1 P.M. & 141 \\
3 & 1P.M. - 7 P.M. & 112 \\
4 & 7P.M. - 5 A.M. & 104 \\
\hline
\end{tabular}


Table 8. Type of repair.

\begin{tabular}{ccc}
\hline S.NO & TOR & WORKERS \\
\hline 1 & PSS & 128 \\
2 & SKIN GRAFTING (SSG, FTSG) & 77 \\
3 & FLAP & 65 \\
4 & TENDON REPAIR & 51 \\
5 & NERVE REPAIR & 24 \\
6 & NERVE RECONSTRUCTION & 25 \\
7 & FRACTURE FIXATION & 15 \\
8 & REVASCULARISATION AND REIMPLANTATION & 31 \\
9 & SHORTENING AND CLOSURE & 117 \\
10 &
\end{tabular}

Table 9. Possible causative \& contributing factors.

\begin{tabular}{ccc}
\hline S.NO & P.CAS \& CON. FACTORS & WORKERS \\
\hline 1 & COWORKER'S CARELESSNESS & 124 \\
2 & MACHINERY MALFUNCTION & 40 \\
3 & NOPROTECTION & 68 \\
4 & EXTRAWORK & 34 \\
5 & WORKER'S CARELESSNESS & 90 \\
6 & FATIGUE & 30 \\
7 & LACK OF SLEEP & 25 \\
8 & HURRY & 20 \\
9 & HUNGER & 19 \\
10 & UNFAMILIAR MACHINE & 48 \\
\hline
\end{tabular}

Table 10. Safety precautions.

\begin{tabular}{crcc}
\hline S.NO & SAFETY PRECAUTIONS & YES & NO \\
\hline 1 & SAFETY TRAINING & $85 \%$ & $15 \%$ \\
2 & SAFETY DESIGN INSTALLED & $72 \%$ & $28 \%$ \\
3 & ACCEPTABLE MACHINE DESIGN & $42 \%$ & $58 \%$ \\
\hline
\end{tabular}

Table 11. Job exeperience.

\begin{tabular}{ccc}
\hline S.NO & JE & WORKERS \\
\hline 1 & $0-6$ months & 180 \\
2 & $6-3$ years & 147 \\
3 & $>3$ years & 92 \\
\hline
\end{tabular}


Table 12. Disability and deofrmity at 3 months.

\begin{tabular}{ccc}
\hline S.NO & PD & WORKERS \\
\hline 1 & RESIDUAL DISABILITY & \\
A & ADL & $2 \%$ \\
B & PROFESSIONAL & $10 \%$ \\
2 & RESIDUAL DEFORMITY & \\
A & LOSS OF DIGITS & $26 \%$ \\
B & STIFFNESS & $16 \%$ \\
C & CONTRACTURE & $12 \%$ \\
3 & No. of working days lost & \\
& 2 weeks - 4 weeks & $20 \%$ \\
& 4 weeks - 8 weeks & $76 \%$ \\
& $>8$ weeks & $4 \%$ \\
\hline
\end{tabular}

\begin{tabular}{cccc}
\multicolumn{4}{l}{ Table 13. Relation of treatment time and final outcome. } \\
\hline Time lapse & No. of patients & \% dis for adl at 3 mo & $\%$ dis for prof act 3 \\
\hline$<6$ hrs & 178 & $2.30 \%$ & $11 \%$ \\
6 - 12 hrs & 65 & $3.00 \%$ & $14.60 \%$ \\
$12-24$ hrs & 145 & $16.20 \%$ & $30.50 \%$ \\
$>24$ hrs & 41 & $17.80 \%$ & $40.70 \%$ \\
\hline
\end{tabular}

factors in causing injury. We suggest holding morning assembly, prayer sessions or yoga sessions before a worker enters his workplace to avoid such injuries. In case of occurrence of injury appropriate first aid, shifting to hand injury centers within the first few hours can significantly decreases the disability occurring due to hand injuries. Hand injury centers should be equipped with operating microscope and instruments with round the clock availability of hand surgeons and a dedicated physiotherapy and rehabilitation team. Physiotherapy must be systematic and constantly supervised by the hand surgeon with application of multi modality approach. From the industry point of view adequate breaks, recreation facilities, counseling team should be provided [15]. On occurrence of injury appropriate first aid, transport, emotional support, adequate rehabilitation and compensation go a long way in gaining confidence of workers.

\section{References}

[1] Larsen, C.F., Mulder, S., Johansen, A.M.T. and Stam C. (2004) The Epidermiology of Hand Injuries in the Netherlands and Denmark. European Journal of Epidemiology, 19, 323-327. http://dx.doi.org/10.1023/B:EJEP.0000024662.32024.e3

[2] Aksan, A.D., Ada, R.D.S., Kayalar, M., AKSU, F. and Bal, E. (2010) Epidermiology of Injuries Treated at Hand \& Microsurgery Hospital. Acta Orthopaedica et Traumatologica Turcica, 44, 352-360.

[3] National Burden of Disease and Cost Effectiveness Study Final Report on Burden of Disease (Book in Turkish). RSHMB, Ankara.

[4] Garg, R., Chung, J. P.Y., Fung, B.K.K. and Ip, W.Y. (2012) Epidermiology of Occupational Hand Injuries in Hongkong. Hong Kong Medical Journal, 18, 131-136.

[5] Serinken, M., Karcioglu, O. and Sener, S. (2008) Occupational Hand Injuries Treated at a Tertiary Care Facility in Western Turkey. Industrial Health, 46, 239-246 http://dx.doi.org/10.2486/indhealth.46.239

[6] Mo, F., Choi, B.C.K., Clottey, C., LeBrun, B. and Robbins, G. (2002) Charecteristics and Risk Factors for Accident Injury in Canada from 1986 to 19996: An Analysis of the Canadian Accident Injury Reporting and Evaluation (CAIRE) Database. Injury Control and Safety Promotion, 9, 73-81. http://dx.doi.org/10.1076/icsp.9.2.73.8701

[7] Chau, N., Bhattacherjee, A., Kunar, B.M. and Group, L. (2009) Relationship between Job, Lifestyle, Age and Occupational Injuries. Occupational Medicine, 59,114-119. http://dx.doi.org/10.1093/occmed/kqp002

[8] Grimsmo-Powney, H., Haris, E.C., Reading, I. and Cogyon, D. (2010) Occupational Health Needs of Commercial Fi- 
sherman in Southwest England. Occupational Medicine, 60, 49-53. http://dx.doi.org/10.1093/occmed/kqp137

[9] Sarock, G.S., Lambordi, D.A., Hauser, R., Eisen, E.A., Herrick, R.F. and Mittleman, M.A. (2004) A Case-Crossover Study of Transient Risk Factor for Occupational Hand Injuries. Occupational and Environmental Medicine, 61, 305-311. http://dx.doi.org/10.1136/oem.2002.004028

[10] Porac, C. (1993) Hand Preference and the Incidence of Accidental Unilateral Hand Injury. Neuropsychologia, 31, 355-362. http://dx.doi.org/10.1016/0028-3932(93)90159-W

[11] Skalkidou, A., Petridou, E., Dessypris, N., Karanikas, E., Pistevos, G. and Trichopoulos, D. (1999) Risk of Upper Limb Injury in Left Handed Children: A Study in Greece. Injury Prevention, 5, 68-71. http://dx.doi.org/10.1136/ip.5.1.68

[12] Chow, C.Y., Lee, H., Lau, J. and Yu, I.T. (2007) Transient Risk Factor for Acute Traumatic hand Injuries: A Case-Crossover Study in Hongkong. Occupational and Environmental Medicine, 64, 47-52. http://dx.doi.org/10.1136/oem.2006.028589

[13] Ihekire, O., Salawu, S.A. and Opadele, T. (2010) International Surgery: Causes of Hand Injuries in a Developing Country. Canadian Journal of Surgery, 53, 161-166.

[14] Grunert, B.k., Hargarten, S.W., Matioub, H.S., Sanger, J.R., Hanel, D.P. and Yousif, N.J. (1992) Predictive Value of Psychological Screening in Acute Hand Injuries. The Journal of Hand Surgery, 17, 196-199. http://dx.doi.org/10.1016/0363-5023(92)90389-7

[15] Hill, C., Riaz, M., Mozzam, A. and Brennen, M.D. (1998) A Regional Audit of Hand and Wrist Injuries. A Study of 4873 Injuries. Journal of Hand Surgery, 23, 169-200. http://dx.doi.org/10.1016/S0266-7681(98)80174-5 


\section{Appendix 1: Proforma for Hand Injuries}

NAME:

AGE \& GENDER: Yrs M/F

HANDEDNESS: RIGHT HANDED/LEFT HANDED OCCUPATION:

IP. NO: OP. NO:

DATE \& TIME OF INJURY PHONE NUMBER: ADDRESS:

MODE OF INJURY O RTA O DOMESTIC O INDUSTRIAL

INSURED/NON-INSURED

RTA:

DOMESTIC:

INDUSTRIAL: SAFETY AWARENESS/POSSIBLE CONTRIBUTING FACTOR/TYPE OF INJURY/ MAGNITUDE OF FORCE

DIAGNOSIS:

PROCEDURE:

DATE OF PROCEDURE:

SURGEON: Dr.

THERAPIST:

COMPLICATIONS: IMMEDIATE:

LATE:

REMOTE:

PHYSIOTHERAPY:

\begin{tabular}{ccc}
\hline WEEK & THERAPY GIVEN & RESULT \\
\hline $1^{\text {st }}$ & \\
$2^{\text {nd }}$ & \\
$3^{\text {rd }}$ & \\
$4^{\text {th }}$ & \\
AFTER 4 WEEKS &
\end{tabular}

SPECIAL AIDS:

ACTIVITIES OF DAILY LIVING:

RESIDUAL PROBLEMS \& DISABILITY (AFTER 2 MONTHS):

NO. OF WORKING DAYS LOST:

SOCIO ECONOMIC STATUS: 


\section{Appendix 2: Questionnaire on Industrial Health}

1) What is the capacity (strength) of workers in a batch/unit?

80 TO 2500

2) Usual working hours per day in a shift? 8 HOURS

3) Maximum how many days a week does a worker work without a break?

6 DAYS

4) How many hours of overtime are allotted at a stretch?

HALF HOUR TO FOUR HOURS

5) Are there any shifts? Please specify MORN, AFTERNOON AND NIGHT 8 HRLY

If yes, how often are the shifts changed?

6) a) Is there any pre placement screening conducted? YES—96\% NO-4\%

b) What factors are included in screening? MEDICAL, BLOOD TESTS

c) Who conducts the screening? DOCTOR- $87 \%$ NURSE— $9 \%$ SAFETY OFFICER $-4 \%$

7) Are health checkups conducted? How often? MONTHLY TO YEARLY

8) Does every newly appointed worker undergo a formal training programme? YES-100\%

9) How long is the training period? 3 - 6 MONTHS

10) Are they taught about safety measures \& work place ergonomics? YES-89\% NO-11\%

11) Is basic first aid \& emergency care also included in the training programme? YES—64\% NO—36\%

12) Do trainees get health insurance? YES-36\% NO-64\%

13) What measures are taken to check the safe working?

(E.g.: Do you have supervisors or mechanical safety devices or follow strict ALL 50\% FEW 43\% NONE 7\% rules at work and penalize the careless workers etc.)

14) How often is a worker allowed to take a break in a day? For how long? AVERAGE THREE BREAKS TOTAL 1 HOUR

15) What measures are taken to improve their working morale?

- Is there a psychological Counsellor? YES-13\% NO-87\%

- Are any recreational activities like games/competitions/prayers/picnics/ festival celebrations etc conducted? YES-67\% NO-33\%

16) No of incidences of industrial accidents reported last year? NONE TO 80/YEAR

17) Approximate cost of amount spend on their compensation annually? 40,000INR TO 15 LAKHS

18) What alternatives are provided for a worker who suffers permanent disability (E.g. annual compensations/ change of role/none)

ALL 66\% FEW 29\% NONE 5\% 